\title{
Analysis of Genial Tubercle Anatomy Using Cone Beam Computed Tomography - A Retrospective Study from Chennai, India
}

\author{
Abarna Jawahar'1, Maragathavalli Gopal ${ }^{2}$ \\ 1,2 Department of Oral Medicine and Radiology, Saveetha University, Saveetha Institute \\ of Medical and Technical Sciences, Maharashtra, India
}

\section{ABSTRACT}

\section{BACKGROUND}

Analysis of genial tubercle anatomy using three-dimensional (3D) imaging can be valuable in preparation for genioglossus advancement in the treatment of obstructive sleep apnoea, estimation of the safe zone prior to implant surgery and evaluation of mandibular asymmetry. Hence the intention of the study was to analyse the morphological pattern, dimensions of genial tubercles and their position in the mandible using cone beam computed tomography (CBCT).

\section{METHODS}

A retrospective study was conducted on 100 patients scanned using Sirona Orthophos XG device in the Radiology department, Saveetha dental college and hospital. The genial tubercles were identified, morphological pattern of the genial tubercles was classified into four patterns and linear measurements of the genial tubercle height, width, position of genial tubercles on the mandible in the images were done. The collected data was tabulated and analysed using SPSS software. A paired $t$ - test was used for intra examiner calibration and a chi-square test was used for comparison between genial tubercle patterns in both the sex.

\section{RESULTS}

On analysing the genial tubercle patterns, type I (44) was the most commonly seen followed by type II (24). Genial tubercles were not evident (type IV) in 20 patients. Type III (12) was least commonly seen among the pattern types.

\section{CONCLUSIONS}

The anatomy of genial tubercles is highly variable. The mean height of genial tubercles (GTH) measured was $5.36 \mathrm{~mm}$ and mean width of genial tubercles (GTW) measured was $5.24 \mathrm{~mm}$.

\section{KEY WORDS}

Genial Tubercles, Anatomy, Cone Beam Computed Tomography, Mandible
Corresponding Author: Dr. Maragathavalli Gopal, Dept. of Oral Medicine and Radiology, Saveetha University, Saveetha Institute of Medical and Technical Sciences, Maharashtra, India.

E-mail:drgopalvalli@gmail.com

\section{DOI: $10.14260 /$ jemds/2021/676}

How to Cite This Article:

Jawahar A, Gopal M. Analysis of genial tubercle anatomy using cone beam computed tomography - a retrospective study from Chennai, India J Evolution Med Dent Sci 2021;10(38):3333-3337, DOI: 10.14260/jemds/2021/676

Submission 02-06-2021,

Peer Review 24-08-2021,

Acceptance 03-09-2021,

Published 20-09-2021.

Copyright (C) 2021 Abarna Jawahar et al. This is an open access article distributed under Creative Commons Attribution License [Attribution 4.0 International (CC $B Y 4.0)]$ 


\section{BACKGROUND}

Genial tubercles also known as mental spines, spinae mentalis or genial apophysis are tiny bony projections seen on the lingual surface of the mandible. They are a group of four bony projections surrounding the lingual foramen, located between the superior and inferior border of mandible. These bony projections give attachment to genioglossus muscle superiorly and geniohyoid muscle inferiorly.1,2 These muscle actions are associated with mobility of the tongue and deglutition which are essential for speech and mastication of food. ${ }^{3}$ Traditionally genial tubercles are outlined as 2 pairs of bony projections situated one above the other in the lingual region of mandibular symphysis, but several variations in their anatomy can also be observed. Sometimes excessive movements of the tongue can result in elevated bony projections making it vulnerable to the site of alveolar fracture.

Cone beam computed tomography (CBCT) is an advanced imaging modality, which allows three-dimensional visualization of hard tissue structures. It has been proved to be a successful investigative modality by providing accurate three-dimensional volumetric data in axial, sagittal and coronal planes which can be useful in diagnosing and treating several pathologies in oral and maxillofacial region. CBCT has several applications in dentistry which includes implantology, oral medicine and surgery, endodontics, orthodontics, and periodontics. It has also been expanded in various fields of medical sciences. Radiation exposure from CBCT is comparatively ten folds lower than exposure from conventional CT scans. ${ }^{4}$ The main advantages of CBCT include easy accessibility, easy handling, in office imaging and offer a real time data set with multiplanar cross-sectional and 3dimensional reconstruction based on a single scan. .-7 $^{5-}$

Analysis of genial tubercle anatomy using cone beam computed tomography for its examination can be helpful in preparation for the surgical advancement of genioglossus for correction of sleep apnoea disorder 8,9 , for planning implant surgery in the interforaminal zone of mandible ${ }^{10}$ and assessing the symmetry of mandible. ${ }^{11}$ Severe atrophy can be seen in the edentulous mandibles of old patients. If the genial tubercles prevail as sharp projections in the mandible of these patients, they can cause significant difficulty to prosthodontists. ${ }^{12-14}$

Hence it is essential to study the different morphological patterns observed in genial tubercles and their relative position in the mandibular region. The purpose of the study was to analyse the patterns of the genial tubercles, their anatomy and position in the mandible with respect to the mandibular anterior teeth and borders using cone beam computed tomography.

\section{METHODS}

A retrospective study was conducted on 100 patients scanned using Sirona Orthophos XG device in the Department of Oral Medicine and Radiology, Saveetha dental college and hospital taken for the purpose of implant placement between September 2020 and February 2021. A sample size of 100 was obtained by using $\mathrm{G}$ power with a power of 80 . The inclusion criteria included good quality CBCT images and patients aged between 20 and 60 years. The exclusion criteria included any congenital or developmental deformities, traumatic injury or pathologic changes in the mandible, any crown or implant placed in the mandibular anterior region and blurred or distorted CBCT images.

Using Galileo's software, the genial tubercles were identified, the pattern of the GT was assessed, and linear measurements of the images were done in each included CBCT volume. To standardize the measurements CBCT scans were oriented, so that the zygomatic structures bilaterally were at the same level in the axial view. In the coronal view the infra orbital foramina of the right and left sides were parallel to the horizontal line. The Frankfort plane represented the true horizontal axis in the sagittal view. To reduce measurement error, all measurements were repeated on 2 separate occasions in 1 - week interval and the average values were recorded. Differences between the 2 readings for intra examiner variation were tested by using paired $t$ tests.

\section{Genial Tubercle Pattern Assessment}

The morphological patterns of the genial tubercles were analysed and grouped into four patterns as follows - a rough impression of two superior genial tubercles (Type I), two superior genial tubercles and a median ridge representing fusion of inferior genial tubercles below them (Type II), a single median ridge (Type III) and no prominent genial tubercles (Type IV). The morphological patterns of the genial tubercles were analysed in the tangential view along with the axial view (Figure 1).

\section{Genial Tubercle Size \& Position Assessment}

Genial tubercle height (GTH) and Genial tubercle width (GTW) were measured in millimetres. Genial tubercle height (GTH) was measured in the cross-sectional view as the vertical distance between the level of the most superior and most inferior border of the genial tubercles (Figure 2a). Genial tubercle width (GTW) was measured in the axial view as the horizontal distance at the widest level between the genial tubercles (Figure 2b). Distance from the apex of the lower central incisors to the superior border of the genial tubercles (I - SGT) and distance from the inferior border of the genial tubercles to the inferior border of the mandible (IGT - IBM) were measured in millimetres. I - SGT and IGT - M were measured in the cross- sectional view by drawing tangent lines from the apex of the lower central incisors to the superior border of the GTs and from the inferior border of the GTs to the inferior border of the mandible (menton), respectively (Figure 2c \& 2d).

\section{Statistical Analysis}

The collected data was tabulated and analysed using SPSS software 23.0 for windows. A paired $t$ - test was used for intra examiner calibration and a chi-square test was used for comparison between genial tubercle patterns in both the sex. A statistically significant test was inferred when the $P$ value was

0.005 


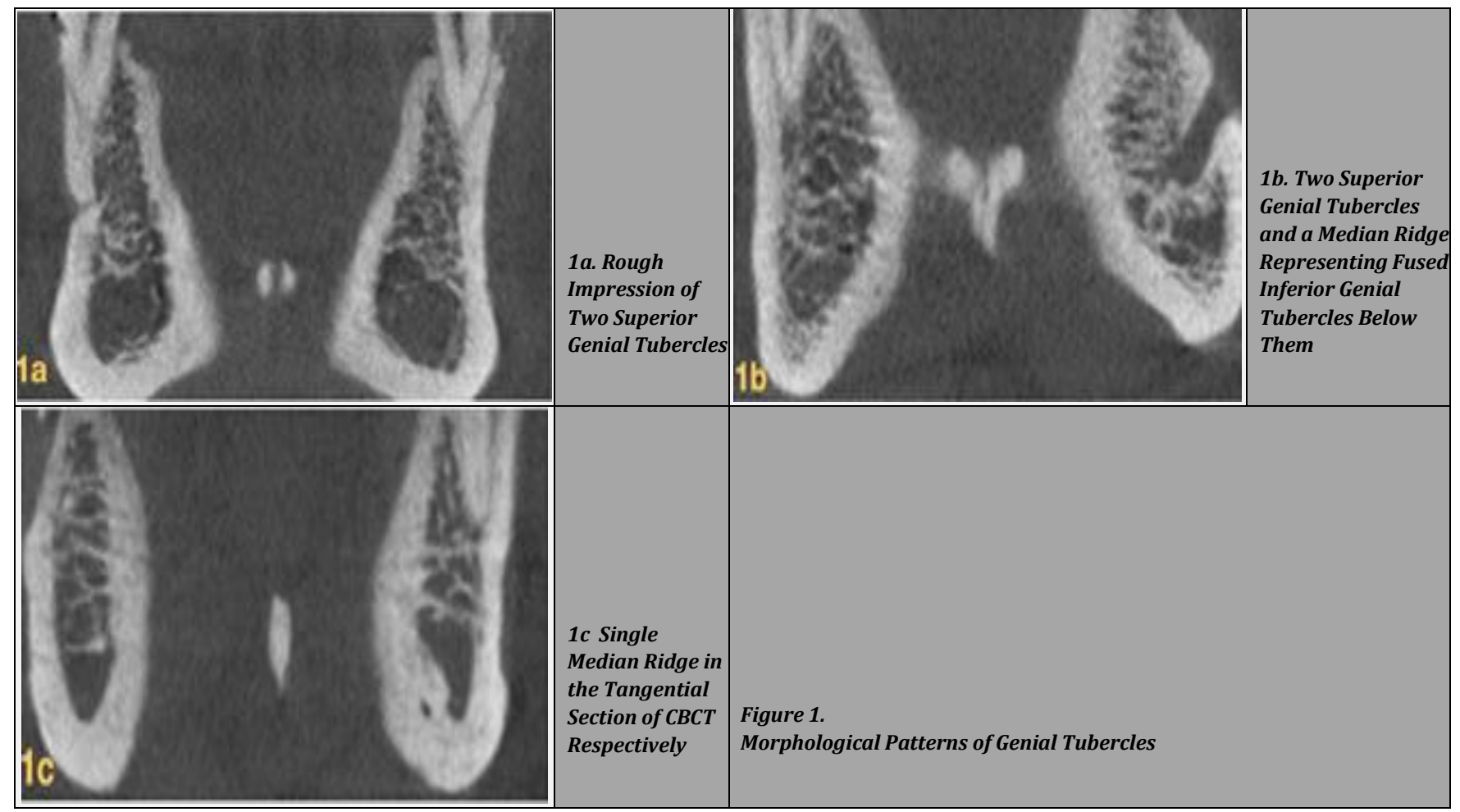

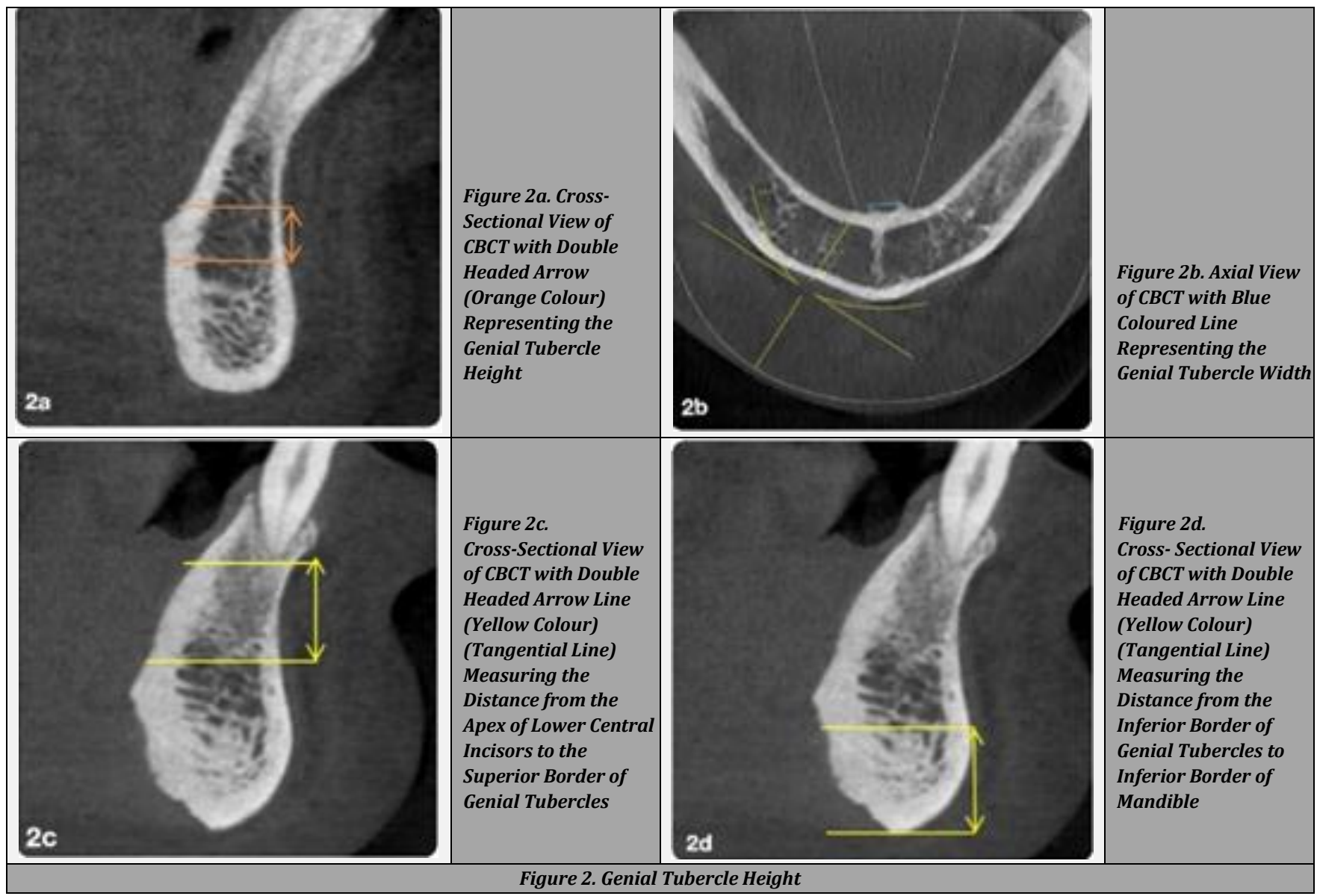

\section{RESULTS}

Data extraction was done from 100 patients in the age group of 20 - 60 years including both the sexes who underwent CBCT imaging for implant planning in the Radiology department of Saveetha Dental College and Hospital who fulfilled the inclusion and exclusion criteria. Paired $t$ - test used to assess the intra-examiner reliability showed statistically no significant difference between the values measured in the two images $(\mathrm{P}>0.05)$. There was nearly 
perfect agreement $\mathrm{P}=0.94$ for the measurements and $\mathrm{P}=$ 0.92 for the pattern distribution.

\begin{tabular}{|cccc|}
\hline Intra-Examiner Reliability & \multicolumn{4}{c|}{ Mean Standard Deviation P Value } \\
\hline Linear Measurements of Genial Tubercles & -.04500 & 1.25 & 0.94 \\
Assessment of Genial Tubercle Pattern & -.7000 & 16.38 & 0.92 \\
\hline \multicolumn{4}{|c|}{ Table 1. Assessment of Intra-Examiner Reliability } \\
\hline
\end{tabular}

The sex distribution among the study population was 62 males and 38 females. On analysing the genial tubercle patterns (Figure 3) type I (44) was the most commonly seen followed by type II (24). Genial tubercles were not evident (type IV) in 20 patients. Type III (12) was least commonly seen among the pattern types. On analysing the correlation of the pattern of the GTs with sex, there was no statistically significant difference between sexes at $\mathrm{P} \leq 0.005$ using the chi - square test (Figure 4).
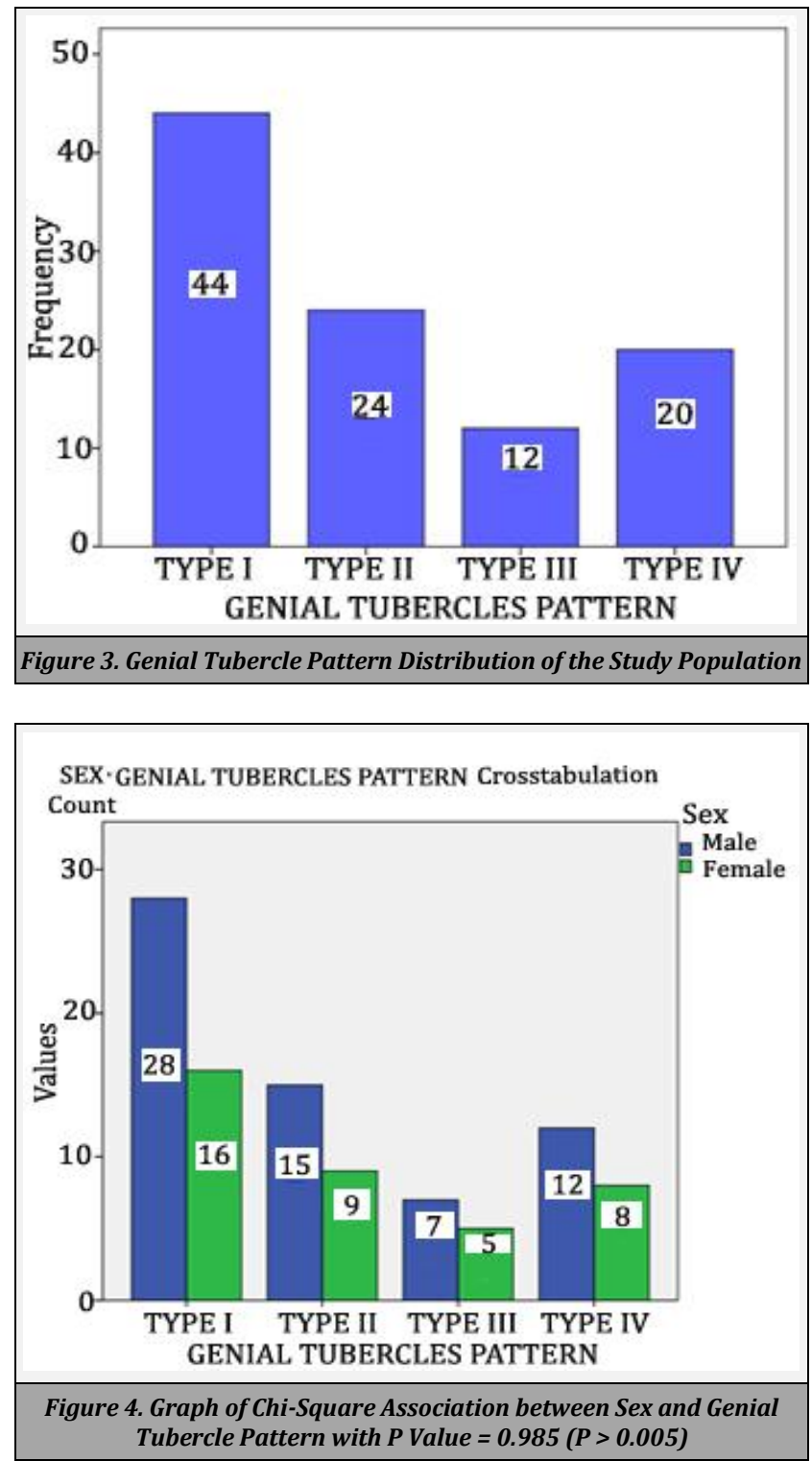

\begin{tabular}{|ccccc|}
\hline Dimensions & Mean & Standard Deviation & Minimum & Maximum \\
Height & $5.36 \mathrm{~mm}$ & $3.04 \mathrm{~mm}$ & $3.41 \mathrm{~mm}$ & $8.27 \mathrm{~mm}$ \\
Width & $5.24 \mathrm{~mm}$ & $1.93 \mathrm{~mm}$ & $3.15 \mathrm{~mm}$ & $8.06 \mathrm{~mm}$ \\
I - SGT & $6.12 \mathrm{~mm}$ & $2.70 \mathrm{~mm}$ & 0 & $12.03 \mathrm{~mm}$ \\
IGT - IBM & $8.90 \mathrm{~mm}$ & $3.07 \mathrm{~mm}$ & $6.19 \mathrm{~mm}$ & $12.93 \mathrm{~mm}$ \\
\hline \multicolumn{5}{c}{ Table 2. Dimensions of the Genial Tubercle } \\
\hline
\end{tabular}

Table 2. shows the values of the dimensions of the genial tubercles observed in our study population. The mean height of genial tubercles (GTH) measured was $5.36 \mathrm{~mm}$ and mean width of genial tubercles (GTW) measured was $5.24 \mathrm{~mm}$. The mean distance between the apex of the lower central incisors and the superior border of the genial tubercles (I - SGT) was $6.12 \mathrm{~mm}$ and distance between the inferior border of the genial tubercles and the inferior border of the mandible (IGT - IBM) was $8.90 \mathrm{~mm}$.

\section{DISCUSSION}

In this study CBCT was used for analysing the genial tubercle anatomy, identifying their morphological patterns, evaluating the dimensions of the genial tubercles and their position in the mandible. Compared with conventional CT imaging, CBCT imaging have been considered as a dose - sparing technique for visualization of important structures before surgeries. The effective dose (ICRP 2007) from a standard dental protocol scan using medium - FOV dental CBCT scans is 1.5 to 12.3 times lesser than that of comparable traditional CT. CBCT has clear advantages over multidetector computed tomography (MDCT) in terms of a low radiation dose, high resolution and allowing export of individualized, overlap free reconstructive images. ${ }^{15}$ The image quality of CBCT scans has also been found to be equivalent to that of traditional CT for visualization of maxillofacial structures.16-18 Several studies have demonstrated that cone beam computed tomography has showed good level of precision in measuring the dimensions of maxilla and mandible. ${ }^{19}$

The genial tubercles are less studied anatomical landmarks by the maxillofacial radiologists. The structural pattern of genial tubercles is variable and debatable; conventionally, it has been described as four bony projections situated in the anterior mandibular region lingually at equidistant between the upper and lower edges that are arranged in pairs and surround the lingual foramina bilaterally. Nevertheless, several studies have shown various differences in the structural anatomy of genial tubercles.

On examining the genial tubercle in CBCT, 4 morphological patterns were observed in our study population. Type I pattern (rough impression of two superior genial tubercles) was the most commonly seen followed by type II (two superior genial tubercles and a single ridge representing fused inferior genial tubercles below them). Type III pattern of single median ridge was seen in 12 patients. Type IV pattern of no evident genial tubercles was the least commonly seen in the study population. The classic description of two superior and inferior genial tubercles was not the most commonly observed morphological pattern in our study population. This study finding was similar to the results of previously conducted osteological studies by Singh et al. and Oda et al. ${ }^{20,21}$

The mean height and width of the genial tubercles in our study population was $5.36 \mathrm{~mm}$ and $5.24 \mathrm{~mm}$ respectively. The study finding was varying from previous study done by Wang et al.22 on Taiwanese population. CBCT measurements of the genial tubercle's height ranged from 6.5 to $7.8 \mathrm{~mm}$ and width was 7.1 to $8.1 \mathrm{~mm}$. Our study finding was similar to results obtained by Yin et al. ${ }^{16}$ study in Chinese patients. The 
morphometric analysis of the genial tubercles in spiral computed tomography revealed the height as $6.17 \pm 0.71 \mathrm{~mm}$ and width as $7.01 \pm 1.13$.

The mean distance between the apex of the lower central incisors and the superior border of the genial tubercles (I SGT) was $6.12 \mathrm{~mm}$ and distance between the inferior border of the genial tubercles and the inferior border of the mandible (IGT - IBM) was $8.90 \mathrm{~mm}$ in our study population.

\section{CONCLUSIONS}

The anatomy of genial tubercles is highly variable. The most common pattern among the studied sample was type I with 2 superior genial tubercles. The mean genial tubercle height was $5.36 \mathrm{~mm}$ and mean genial tubercle width was $5.24 \mathrm{~mm}$. The analysis of genial tubercle anatomy using CBCT has clinical significance in the preparation for surgical advancement of genioglossus for correction of sleep apnoea disorder, for planning implant surgery in the interforaminal zone of mandible and assessing the symmetry of mandible.

Data sharing statement provided by the authors is available with the full text of this article at jemds.com.

Financial or other competing interests: None.

Disclosure forms provided by the authors are available with the full text of this article at jemds.com.

\section{REFERENCES}

[1] Djindjian R, Merland JJ. Normal super - selective arteriography of the external carotid artery. In: Djindjian R, Merland JJ, eds. Super - selective arteriography of the external carotid artery. Berlin, Heidelberg: Springer 1978: p. 1-123.

[2] Taub PJ, Patel PK, Buchman SR, et al. Ferraro's Fundamentals of Maxillofacial Surgery. New York, NY, USA: Springer 2015.

[3] Ryan JM, Ross D, Obeid G. Genial tubercle fracture: a case report and review of the literature. J Oral Maxillofac Surg 2010;68(9):2338-41.

[4] Kumar M, Shanavas M, Sidappa A, et al. Cone beam computed tomography - know its secrets. J Int Oral Health 2015;7(2):64-8.

[5] Loubele M, Bogaerts R, Van Dijck E, et al. Comparison between effective radiation dose of CBCT and MSCT scanners for dentomaxillofacial applications. Eur J Radiol 2009;71(3):461-8.

[6] Fatemitabar SA, Nikgoo A. Multichannel computed tomography versus cone - beam computed tomography: linear accuracy of in vitro measurements of the maxilla for implant placement. Int J Oral Maxillofac Implants 2010;25(3):499-505.

[7] De Vos W, Casselman J, Swennen GRJ. Cone - beam computerized tomography (CBCT) imaging of the oral and maxillofacial region: a systematic review of the literature. Int J Oral Maxillofac Surg 2009;38(6):609-25.
[8] Barbick MB, Dolwick MF. Genial tubercle advancement for obstructive sleep apnea syndrome: a modification of design. J Oral Maxillofac Surg 2009;67(8):1767-70.

[9] Hueman EM, Noujeim ME, Langlais RP, et al. Accuracy of cone beam computed tomography in determining the location of the genial tubercle. Otolaryngol Head Neck Surg 2007;137(1):115-8.

[10] Voon YS, Patil PG. Safe zone in anterior mandible related to the genial tubercle for implant osteotomy in a Chinese - Malaysian population: A CBCT study. J Prosthet Dent 2018;119(4):568-73.

[11] Lee SY, Choi DS, Jang I, et al. The genial tubercle: a prospective novel landmark for the diagnosis of mandibular asymmetry. Korean J Orthod 2017;47(1):508.

[12] Păuna MR, Babiuc I, Farcaşiu AT. Prosthodontic management of an extreme atrophy of the mandible correlated with a prominent genial tubercle - a clinical report. Rom J Morphol Embryol 2015;56(Suppl 2):86770.

[13] Solomon EGR. A critical analysis of complete denture impression procedures: contribution of early prosthodontists in India - part I. J Indian Prosthodont Soc 2011;11(3):172-82.

[14] Shohat I, Shoshani Y, Taicher S. Fracture of the genial tubercles associated with a mandibular denture: a clinical report. J Prosthet Dent 2003;89(3):232-3.

[15] Orhan K, Aksoy S, Bilecenoglu B, et al. Evaluation of bifid mandibular canals with cone - beam computed tomography in a Turkish adult population: a retrospective study. Surg Radiol Anat 2011;33(6):501-7.

[16] Liang X, Jacobs R, Lambrichts I, et al. Lingual foramina on the mandibular midline revisited: a macroanatomical study. Clin Anat 2007;20(3):246-51.

[17] Periago DR, Scarfe WC, Moshiri M, et al. Linear accuracy and reliability of cone beam CT derived 3 - dimensional images constructed using an orthodontic volumetric rendering program. Angle Orthod 2008;78(3):387-95.

[18] Ludlow JB, Gubler M, Cevidanes L, et al. Precision of cephalometric landmark identification: cone - beam computed tomography vs conventional cephalometric views. Am J Orthod Dentofacial Orthop 2009;136(3):312.e1-10; discussion 312-3.

[19] Ludlow JB, Laster WS, See M, et al. Accuracy of measurements of mandibular anatomy in cone beam computed tomography images. Oral Surg Oral Med Oral Pathol Oral Radiol Endod 2007;103(4):534-42.

[20] Singh V, Anand MK, Dinesh K. Variations in the pattern of mental spines and spinous mental foramina in dry adult human mandibles. Surg Radiol Anat 2000;22(3-4):16973.

[21] Oda LS, Iyomasa MM, Watanabe IS. Morphologic analysis of the 'spina mentalis' in adult mandibles of Brazilian whites and negroes. Rev Bras Pesqui Med Biol 1977;10(6):357-60.

[22] Wang YC, Liao YF, Li HY, et al. Genial tubercle position and dimensions by cone - beam computerized tomography in a Taiwanese sample. Oral Surg Oral Med Oral Pathol Oral Radiol 2012;113(6):e46-50. 